
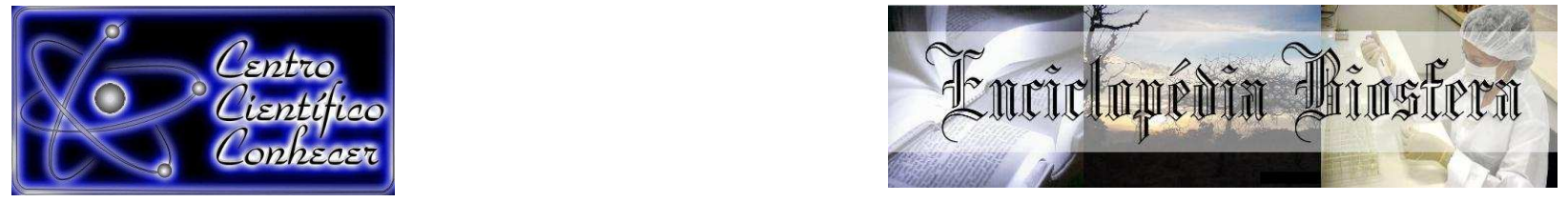

\title{
INFLUÊNCIA DE DIFERENTES FONTES DE MATÉRIA ORGÂNICA NO SUBSTRATO DE MUDAS DE Passiflora Morifolia
}

\author{
Ramon Amaro de Sales ${ }^{1 *}$; Clodoaldo Spadeto Ambrozim²; Yago Tonini da Vitória ${ }^{3}$; \\ Ricardo Amaro de Sales ${ }^{4}$; Sávio Silva Berilli ; \\ ${ }^{1 * 2 ; 4}$ Bolsista de Iniciação Científica, Engenharia Agronômica, Instituto Federal de \\ Educação do Espírito Santo - IFES, Campus Itapina, Colatina, Brasil. \\ (ramonamarodesales@gmail.com) \\ ${ }^{3}$ Engenharia Agronômica, Instituto Federal de Educação do Espírito Santo - IFES, \\ Campus Itapina, Colatina, Brasil. \\ ${ }^{5}$ Professor Doutor do Instituto Federal de Educação do Espírito Santo - IFES, \\ Campus Itapina, Colatina, Brasil.
}

Recebido em: 03/10/2016 - Aprovado em: 21/11/2016 - Publicado em: 05/12/2016 DOI: 10.18677/EnciBio_2016B 057

\begin{abstract}
RESUMO
O Brasil é considerado o centro de diversidade genética de muitas espécies da família Passifloraceae, destacando-se algumas espécies silvestres como a $P$. morifolia, a qual apresenta potencial para melhoramento genético de resistência ou tolerância as principais doenças do maracujazeiro, como as causadas por $F$. oxysporum, F. solani e Phytophtora sp. Seja para fins de melhoramento genético ou estudos de enxertia visando resistência a doenças, alguns avanços da propagação dessa espécie devem ser estudados, com isso, objetivou-se neste trabalho avaliar a influência de diferentes fontes de matéria orgânica na formação de mudas da espécie Passiflora morifolia Mast. O experimento foi executado em casa de vegetação em um delineamento de blocos casualizados com sete tratamentos, constituído de diferentes fontes de matéria orgânica, como esterco bovino, lodo de curtume, composto de lixo urbano, resíduos da torrefação do café, húmus e testemunhas. Foram avaliadas características de desenvolvimento das plantas, sendo observado que todas as fontes de matéria orgânica usadas promoveram ganho de desenvolvimento em relação a mudas desenvolvidas sem adição de matéria orgânica.
\end{abstract}

PALAVRAS-CHAVE: Adubação alternativa, lodo de curtume, Maracujá-silvestre

\section{INFLUENCE OF DIFFERENT SOURCES OF ORGANIC MATTER IN PASSIFLORA SEEDLING SUBSTRATE MORIFOLIA}

\begin{abstract}
Brazil is considered the genetic diversity center of many species of Passifloraceae, highlighting some wild species such as $P$. morifolia, which has potential for genetic improvement of resistance or tolerance major diseases of passion fruit, such as those caused by F. oxysporum, F. solani and Phytophthora sp. Whether for breeding purposes or grafting studies for disease resistance, some advances of the spread of
\end{abstract}


this species should be studied, therefore, the aim of this study was to evaluate the influence of different sources of organic matter on seedling species Passiflora morifolia Mast. The experiment was performed in a greenhouse in a randomized complete block design with seven treatments, consisting of different sources of organic matter such as manure, tannery sludge, urban waste compost, coffee roasting residues, humus and witnesses. Plant growth characteristics were assessed, observed that all sources of organic matter used promoted development gain compared to seedlings that grew without the addition of organic matter.

KEYWORDS: Passion fruit wild, alternative fertilizer, tannery sludge

\section{INTRODUÇÃO}

O Brasil é destaque como um dos principais produtores mundiais de frutas, entre as frutas produzidas nos pais o maracujá apresenta crescimento expressivo na produção. Os maiores estados produtores são Bahia, Ceará, Espírito Santo, São Paulo e Sergipe, responsáveis por parte da produção nacional (ALBUQUERQUE JUNIOR et al., 2013).

MELETTI (2011) relata que a cultura do maracujá tem se destacado dentro da fruticultura tropical, e é considerada uma alternativa agrícola para diversificação de renda nas propriedades rurais por ser uma frutífera de rápido retorno econômico. Esta fruta é uma planta trepadeira com origem na América tropical pertencentes a ordem Passiflorales, e família das passifloraceae. O maracujazeiro possui propriedades terapêuticas com valor medicinal principalmente por conter passiflorina que é um sedativo natural (ALMEIDA et al., 2015).

A propagação do maracujazeiro pode ocorrer de forma sexuada (seminíferas) ou assexuada (estaquia, enxertia alborquia e culturas de tecidos). No entanto a propagação sexuada é a mais empregada por ser rápida e pela facilidade na formação de mudas (FERREIRA et al., 2002). Essa técnica é utilizada principalmente na produção de mudas em escala comercial, no entanto a propagação por enxertia poderá desempenhar grande importância para a cultura na solução de problemas com pragas e doenças principalmente por algumas espécies de passifloráceas apresentarem resistência a algumas doenças (AGUIAR et al., 2011).

Com intuito de aumentar a qualidade das mudas produzidas vêm sendo estudadas nos últimos anos novas técnicas de cultivo, entre essas técnicas o tipo de substrato vem ganhado destaque (NOGUEIRA et al., 2014). Segundo GONÇALVES et al., (2014), os substratos, são alguns dos diversos fatores que contribuem para produção de mudas com qualidade, sendo uma grande diversidade existente, um substrato nem sempre age de maneira igual para todas as condições e espécies.

GONDIN et al., (2015), ressaltam que o substrato utilizado para a formação de plantas pode variar, influenciando diretamente a germinação. Um exemplo de composto para um substrato alternativo é a utilização de lodo de curtume na agricultura, desde que se tomem os cuidados necessários com esses resíduos, devido a presença de cromo e sódio, os quais podem ser fitotóxicos aos vegetais e causar impactos ambientais indesejados (ARAÚJO et al., 2008).

Os materiais descartados como lixo urbano, de origem orgânica, também podem ser utilizados como substrato por serem ricos em nutrientes e matéria orgânica, sendo este resíduo já testado por alguns pesquisadores no cultivo de plantas (SANTOS et al., 2013). 
Outro substrato muito usado como fonte de nutrientes é o esterco bovino, no qual CANESIN \& CORRÊA (2006), trabalhando com esterco de curral encontraram bons resultados na produção de mudas de mamoeiro, e relataram que o esterco foi capaz de fornecer às mudas de mamoeiro os nutrientes $\mathrm{N}, \mathrm{P}, \mathrm{K}, \mathrm{Ca}, \mathrm{Mg}$ e $\mathrm{Cu}$ necessários para o desenvolvimento até que se possa transplantá-las para o campo.

Objetivou-se neste trabalho avaliar a influência de diferentes fontes de matéria orgânica em substratos para a formação de mudas do maracujazeiro Passiflora morifolia Mast.

\section{MATERIAL E MÉTODOS}

O experimento foi realizado no Instituto Federal de Educação, Ciência e Tecnologia do Espírito Santo - Campus Itapina, localizado no município de Colatina, região noroeste capixaba, com coordenadas geográficas de $19^{\circ} 32^{\prime} 22^{\prime \prime}$ de latitude sul; $40^{\circ} 37^{\prime} 50^{\prime \prime}$ de longitude oeste e altitude de 71 metros. Esse experimento foi conduzido em viveiro de propagação de mudas, com início de plantio dia 19/09/2015 e término 28/09/2015. Foram utilizadas mudas de maracujá silvestre (plassifora morifolia Mast), aplicando um delineamento experimental de blocos casualizados com seis blocos e sete tratamentos, sendo consideradas cinco mudas por tratamento, totalizando assim 35 plantas por bloco, e 210 plantas em todo o experimento. Os tratamentos seguem detalhados no quadro 1.

QUADRO 1 - Tratamentos utilizados para o experimento de propagação da espécie P. morifolia Mast com diferentes fontes de matéria orgânica.

\begin{tabular}{|c|c|}
\hline Tratamento & Componente do substrato \\
\hline $\mathrm{T}-1$ & Controle: $100 \%$ terra de barranco; \\
\hline T-2 & $\begin{array}{l}100 \% \text { terra de barranco }+5 \mathrm{Kg} \text { de superfosfato simples e } 1 \mathrm{Kg} \text { de } \\
\text { cloreto de potássio em um metro cúbico de substrato; }\end{array}$ \\
\hline T-3 & $\begin{array}{l}\text { Uma mistura na proporção de } 75 \% \text { de terra }+25 \% \text { de esterco } \\
\text { bovino curtido. Para a preparação de um metro cubico de } \\
\text { substrato, foi adicionado } 5 \mathrm{Kg} \text { de superfosfato simples e } 1 \mathrm{Kg} \text { de } \\
\text { cloreto de potássio (convencional); }\end{array}$ \\
\hline T-4 & $\begin{array}{l}\text { Uma mistura na proporção de } 75 \% \text { de terra }+25 \% \text { der resíduo da } \\
\text { indústria de torrefação de café. Para a preparação de um metro } \\
\text { cubico de substrato, foi adicionado } 5 \mathrm{Kg} \text { de superfosfato simples e } \\
1 \mathrm{Kg} \text { de cloreto de potássio; }\end{array}$ \\
\hline T-5 & $\begin{array}{l}\text { Uma mistura na proporção de } 75 \% \text { de terra }+25 \% \text { der lodo de } \\
\text { curtume. Para a preparação de um metro cubico de substrato, foi } \\
\text { adicionado } 5 \mathrm{Kg} \text { de superfosfato simples e } 1 \mathrm{Kg} \text { de cloreto de } \\
\text { potássio; }\end{array}$ \\
\hline T-6 & $\begin{array}{l}\text { Uma mistura na proporção de } 75 \% \text { de terra }+25 \% \text { der composto } \\
\text { orgânico de lixão (chamado nesse trabalho de composto urbano). } \\
\text { Para a preparação de um metro cubico de substrato, foi } \\
\text { adicionado } 5 \mathrm{Kg} \text { de superfosfato simples e } 1 \mathrm{Kg} \text { de cloreto de } \\
\text { potássio; }\end{array}$ \\
\hline T-7 & $\begin{array}{l}\text { Uma mistura na proporção de } 75 \% \text { de terra }+25 \% \text { der húmus. } \\
\text { Para a preparação de um metro cubico de substrato, foi } \\
\text { adicionado } 5 \mathrm{Kg} \text { de superfosfato simples e } 1 \mathrm{Kg} \text { de cloreto de } \\
\text { potássio; }\end{array}$ \\
\hline
\end{tabular}

ENCICLOPÉDIA BIOSFERA, Centro Científico Conhecer - Goiânia, v.13 n.24; p. 608 2016 
Dos materiais utilizados, o esterco bovino foi obtido de animais confinados nos currais do IFES campus Itapina, sendo o húmus processado desse esterco, o resíduo de torrefação de café foi adquirido da indústria de café Meridiano, situada no município de Colatina - ES, sendo um resíduo do processamento da torra do café. O lodo de curtume foi cedido pela empresa capixaba Couros LTDA ME, localizada no município de Baixo Guandu - ES e é derivado do processamento do couro bovino após desidratação. O resíduo de composto urbano foi fornecido por uma usina de triagem e compostagem de resíduos sólidos urbanos (UTC) da secretaria municipal do meio ambiente da prefeitura de Montanha.

As mudas foram propagadas em sacos plásticos com dimensões de $11 \times 20 \times 05 \mathrm{~cm}$. O preparo do substrato foi feito com 15 dias de antecedência do plantio das sementes. Utilizaram-se quatro sementes de maracujá silvestre (plassifora morifolia Mast) por saco plástico, e após a germinação, realizou-se o desbaste, permanecendo com uma planta por saco plástico.

Foram feitas avaliações semanalmente, as variáveis: número de folhas; altura da planta (medido do colo até o ápice da planta); diâmetro de copa (foi medido entre as maiores distâncias das folhas da mesma copa). Ao fim do experimento, 40 dias após a semeadura, as mudas atingiram tamanho comercial e houve uma avaliação destrutiva, foram avaliados os parâmetros: área foliar; índice SPAD, que foi realizada com o clorofilômetro soil plant analysis development (SPAD-502 minolta), massa fresca e seca da parte aérea e raiz, assim como massa fresca e seca total da planta. Para a obtenção das massas secas, essas foram colocadas em estufa de circulação forçada a $70^{\circ} \mathrm{C}$ durante $72 \mathrm{hrs}$ e posterior pesagem em balança analítica de precisão.

Durante a condução do experimento foi monitorada a casa de vegetação, e foram observadas: médias de temperatura e umidade relativa do ar (Figura $1 \mathrm{~A}$ ) diária além da luminosidade total diária (Figura 1 B) com início as 06 horas e 12 minutos e término as 17 horas e 12 minutos.

Os resultados foram submetidos ao teste $F$, de modo que havendo significância, foi aplicado o teste de média de Scott-Kinott ao nível de $1 \%$ de probabilidade de erro.
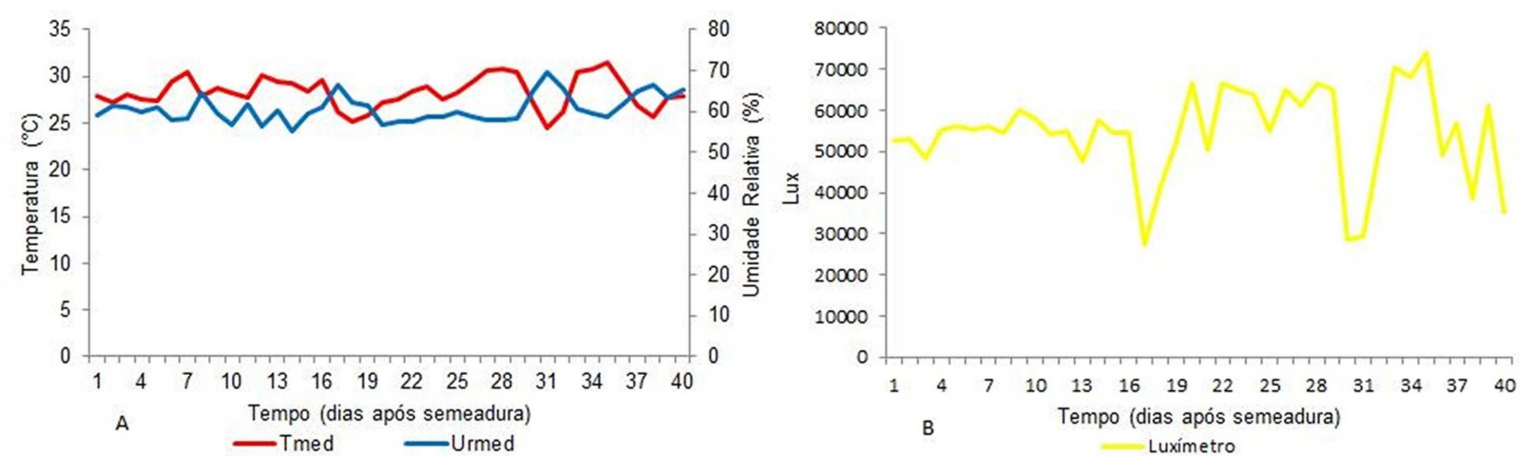

FIGURA 1. Valores médios de temperatura e umidade relativa do ar $(A)$ e soma diária de luminosidade (B).

\section{RESULTADOS E DISCUSSÃO}

Ao avaliar os resultados do uso de diferentes fontes de matéria orgânica presentes no substrato das mudas de maracujá plassifora morifolia Mast, foi possível identificar que em praticamente todos os tratamentos com adição de material 
orgânico, ocorreram ganhos significativos de desenvolvimento para todas as características avaliadas.

Observa-se na Tabela 1 que os tratamentos que utilizaram como fonte de matéria orgânica o esterco bovino, resíduo de torrefação de café, lodo de curtume e lixão industrial juntamente do substrato, não diferem entre si, quando avaliados para número de folhas presentes nas plantas, destacando-se o tratamento que utilizou o lodo de curtume, o qual apresentou cerca de 11 folhas por planta, em comparação com as mudas de terra pura e as mudas com terra mais adubo químico, foi superior em 120 e $37 \%$.

Experimentos feitos por BERILLI et al., (2014) utilizando lodo de curtume com volume de $30 \%$ do total, mostraram eficiência quanto ao número de folhas em mudas de café conilon, apresentando oito folhas após 120 dias. Apesar disso, foi observado por esses autores, que para mudas de café conilon, somente a associação de lodo com terra de subsolo, sem a adição de adubos químicos ou outros compostos orgânicos, não foi o suficiente para produzir mudas com padrões de qualidade satisfatória quando comparado a sistemas convencionais de propagação de café.

Para a emissão do número de folhas, a adição do húmus no substrato foi superior à média das mudas sem adição de matéria orgânica e sem aplicação de adubos, igualando-se as mudas adubadas e sem matéria orgânica. Apesar disso, para essa característica, as outras fontes de matéria orgânica promoveram maior emissão de folhas. Ainda avaliando a característica de número de folhas, foi observado no tratamento com húmus, que mesmo sendo inferior aos outros tratamentos com diferentes fontes de matéria orgânica, ao analisar a área foliar, percebeu-se que essa diferença não existe, revelando que essa característica compensa a diminuição de emissão de folhas em área fotossintética.

A área foliar mostrou ser igual estatisticamente nos tratamentos com adição de algum tipo de matéria orgânica no substrato (Tabela 1), porém pode-se destacar que o T-6 apresentou uma área foliar $1000 \%$ maior quando comparado ao T-1 e $163 \%$ maior quando comparado ao T-2, revelando a influência da matéria orgânica no substrato para o ganho de área fotossintetizante de uma muda. SANTOS et al. (2013), apresentaram os valores de área foliar maiores nos substratos com $100 \%$ húmus de minhoca $(\mathrm{HM})$ e $90 \% \mathrm{HM}+10 \%$ casca de arroz carbonizada, com valores de $90,08 \mathrm{~cm}^{2}$ e $88,04 \mathrm{~cm}^{2}$, respectivamente.

De um modo geral, o tratamento sem adição de adubos ou matéria orgânica (T-1), apresentou rendimento baixo, principalmente devido as limitações nutricionais. BROETTO et al. (2009), avaliando substratos para a produção orgânica de mudas de maracujazeiro-azedo, perceberam que o tratamento que utilizou como substrato apenas a terra pura, apresentou um índice baixíssimo de área foliar em relação aos demais, com 10,93 $\mathrm{cm}^{2}$, comprovando que o insucesso desta prática é previsível.

Os tratamentos com adição de algum tipo de matéria orgânica no substrato foram iguais para as variáveis: altura de planta e diâmetro de copa (Tabela 1), de modo que os tratamentos que apresentaram o melhor desenvolvimento comparado ao substrato com adubado e sem matéria orgânica, foram os T-5 e T-6, superando-o em altura $130 \%$ e $94 \%$ respectivamente e em diâmetro da copa em mais de $40 \%$ para ambos. Os tratamentos T-1 e T-2 foram diferentes, tanto para altura de planta, como para diâmetro de copa, os menores valores se expressaram ambos nos T-1 sendo $5,61 \mathrm{~cm}$ e $6,22 \mathrm{~cm}$, respectivamente. Resultados encontrados por ENCICLOPÉDIA BIOSFERA, Centro Científico Conhecer - Goiânia, v.13 n.24; p. 6102016 
NOGUEIRA FILHO et al. (2011), demonstraram valores de altura de $17,73 \mathrm{~cm}$ aos 45 dias após a enxertia da espécie $P$. Giberti, utilizando como substrato Plantmax, que é composto por uma mistura de casca de Pinus, vermiculita e carvão ativado, na proporção de 3:1:1 (v:v).

Para a medida indireta de clorofila, ou seja, do índice SPAD, observou-se que apenas o tratamento com terra pura foi diferente, os demais foram todos iguais, destacando as plantas adubadas com esterco bovino e lodo de curtume que apresentaram valores superiores àquelas que na composição utilizou apenas terra pura em $52 \%$ e $47 \%$ respectivamente.

Avaliando o crescimento inicial e teor nutricional do maracujazeiro amarelo submetido à adubação com diferentes fontes nitrogenadas, SANTOS et al. (2011), obtiveram índices SPAD de 48,04 aos 127 dias após a semeadura com o esterco bovino, concluindo que o tratamento contendo apenas esterco, apresentou a menor média, revelando valores inferiores àquelas que, além do esterco, receberam adubação mineral com sulfato de amônio, nitrato de amônio ou ureia.

TABELA 1. Médias do número de folha (NF), altura da planta (AP), diâmetro da copa (DCO), área foliar (AF) e Índice SPAD (SPAD) de mudas maracujá silvestre (Plassifora morifolia Mast) cultivadas em diferentes substratos.

\begin{tabular}{lcrrrr}
\hline Tratamento & NF & $\begin{array}{c}\text { AP } \\
(\mathrm{cm})\end{array}$ & $\begin{array}{r}\text { DCO } \\
(\mathrm{cm})\end{array}$ & $\begin{array}{c}\text { AF } \\
\left(\mathrm{cm}^{2}\right)\end{array}$ & SPAD \\
\hline T-1: Terra pura & $5 \mathrm{c}$ & $5.6 \mathrm{c}$ & $6.2 \mathrm{c}$ & $17.3 \mathrm{c}$ & $21.1 \mathrm{~b}$ \\
T-2: Terra + adubo & $8 \mathrm{~b}$ & $18.6 \mathrm{~b}$ & $8.5 \mathrm{~b}$ & $71.1 \mathrm{~b}$ & $27.2 \mathrm{a}$ \\
T-3: Terra + adubo + esterco & $10 \mathrm{a}$ & $33.7 \mathrm{a}$ & $12.1 \mathrm{a}$ & $146.7 \mathrm{a}$ & $32.1 \mathrm{a}$ \\
T-4: Terra + adubo + resíduo de café & $10 \mathrm{a}$ & $32.4 \mathrm{a}$ & $11.1 \mathrm{a}$ & $147.1 \mathrm{a}$ & $30.5 \mathrm{a}$ \\
T-5: Terra + adubo + lodo de curtume & $11 \mathrm{a}$ & $35.0 \mathrm{a}$ & $12.5 \mathrm{a}$ & $147.1 \mathrm{a}$ & $31.2 \mathrm{a}$ \\
T-6: Terra + adubo + composto urbano & $11 \mathrm{a}$ & $41.4 \mathrm{a}$ & $12.1 \mathrm{a}$ & $187.9 \mathrm{a}$ & $28.6 \mathrm{a}$ \\
T-7: Terra + adubo + húmus & $9 \mathrm{~b}$ & $33.8 \mathrm{a}$ & $11.3 \mathrm{a}$ & $157.9 \mathrm{a}$ & $30.4 \mathrm{a}$ \\
\hline Média & 9 & 28.6 & 10.5 & 125.0 & 28.7 \\
\hline CV $(\%)$ & 15.93 & 32.17 & 10.97 & 36.89 & 16.15 \\
\hline
\end{tabular}

Médias seguidas de letras distintas entre si na coluna diferem estatisticamente entre si pelo teste Scott-Knott ao nível de 1\%.

Com relação às análises feitas no laboratório (Tabela 2), ao avaliar a massa fresca da raiz pode-se perceber que os tratamentos com adição de algum tipo de matéria orgânica no substrato mostraram ser iguais estatisticamente entre si, porém pode-se destacar o T-3 que apresentou uma massa fresca da raiz $975 \%$ e $160 \%$ maior nos T-1 e T-2 respectivamente. SANTOS et al. (2012) perceberam que em mudas de maracujá Passiflora cincinnata mast. feito por estaquia presentou após 90 dias de plantio o maior acúmulo de massa fresca, com 1,94 g, sendo utilizado 0 substrato comercial vivatto em recipiente de $288 \mathrm{~cm}^{3}$.

Para a massa fresca da parte aérea, os tratamentos que utilizaram como substrato orgânico o esterco bovino, resíduo de torrefação de café, lodo de curtume e lixão industrial, não diferiram entre si, destacando-se o tratamento que utilizou como substrato o esterco bovino, que apresentou um peso de 4,28 $\mathrm{g}$ aproximadamente, superando a média de mudas que não usaram nenhum tipo de matéria orgânica e sem adubos no substrato em $810 \%$ e $74 \%$ acima das mudas sem matéria orgânica, porém com adubo químico no substrato. 
A adição do húmus no substrato para a massa fresca da parte aérea foi superior à média das mudas sem adição de matéria orgânica e sem aplicação de adubos em 500\%, igualando-se as mudas adubadas e sem matéria orgânica. Apesar do húmus não ter se expressado como os demais tratamentos com substrato orgânico para esta característica, analisando a matéria seca da raiz vê-se que é compensada em $65 \%$ maior que os T-4, sendo este igual aos T-3 e T-5, que também utilizaram fontes de matéria orgânica nos substratos. Por último os T-1 e T-2, que foram diferentes, em que o T-2 superou o T-1 em peso cerca de $400 \%$ em matéria seca da raiz.

Os tratamentos com adição de algum tipo de matéria orgânica no substrato foram iguais estatisticamente para a variável massa seca da parte aérea, apesar de os tratamentos que utilizaram no substrato esterco bovino e lixão industrial mostrarem um maior desenvolvimento em relação aos tratamentos sem adição de matéria orgânica e sem aplicação de adubos ou adubados, mas sem matéria orgânica, onde para os dois substratos obtiveram-se resultados com aproximadamente $2000 \%$ e $120 \%$ maior respectivamente.

Estudos feitos por SILVA et al. (2010), avaliando as variáveis: massa seca da raiz e massa seca da parte aérea para maracujá amarelo (Passiflora edulis Sims. f. flavicarpa Degener, apresentaram peso médio 0,52 e 2,00 g respectivamente, utilizando como substrato solo mais esterco bovino na proporção $2: 1$, em recipiente de $700 \mathrm{~mL}$, sendo esta feita com 67 dias após a semeadura. Os autores WENDLING \& GATTO (2002), relataram que esterco bovino curtido é um componente que traz importantes melhorias quando usado nos substratos devido a propriedades físicas como o aumento da porosidade e a agregação do substrato, e química fornecendo nutrientes às mudas.

TABELA 2. Médias da massa fresca da raiz (MFR), massa fresca da parte aérea (MFPA), massa seca da raiz (MSR), massa seca da parte aérea (MSPA), massa fresca total (MFT) e massa seca total (MST) de mudas de mudas maracujá silvestre (plassifora morifolia Mast) cultivadas em substrato convencional e com diferentes fontes de matéria orgânica.

\begin{tabular}{lcccccc}
\hline Tratamento & $\begin{array}{c}\text { MFR } \\
(\mathrm{g})\end{array}$ & $\begin{array}{c}\text { MFPA } \\
(\mathrm{g})\end{array}$ & $\begin{array}{c}\text { MSR } \\
(\mathrm{g})\end{array}$ & $\begin{array}{c}\text { MSPA } \\
(\mathrm{g})\end{array}$ & $\begin{array}{c}\text { MFT } \\
(\mathrm{g})\end{array}$ & $\begin{array}{c}\text { MST } \\
(\mathrm{g})\end{array}$ \\
\hline T-1: Terra pura & $0.16 \mathrm{~b}$ & $0.47 \mathrm{c}$ & $0.05 \mathrm{~d}$ & $0.05 \mathrm{c}$ & $0.63 \mathrm{c}$ & $0.11 \mathrm{~b}$ \\
T-2: Terra + adubo & $0.67 \mathrm{~b}$ & $2.46 \mathrm{~b}$ & $0.25 \mathrm{c}$ & $0.49 \mathrm{~b}$ & $3.14 \mathrm{~b}$ & $0.75 \mathrm{~b}$ \\
T-3: Terra + adubo + esterco & $1.72 \mathrm{a}$ & $4.28 \mathrm{a}$ & $0.39 \mathrm{~b}$ & $1.06 \mathrm{a}$ & $6.01 \mathrm{a}$ & $1.46 \mathrm{a}$ \\
T-4: Terra + adubo + resíduo de & $1.05 \mathrm{a}$ & $4.26 \mathrm{a}$ & $0.34 \mathrm{~b}$ & $0.91 \mathrm{a}$ & $5.31 \mathrm{a}$ & $1.26 \mathrm{a}$ \\
café & & & & & & \\
T-5: Terra + adubo + lodo de & $1.20 \mathrm{a}$ & $4.20 \mathrm{a}$ & $0.37 \mathrm{~b}$ & $0.99 \mathrm{a}$ & $5.40 \mathrm{a}$ & $1.36 \mathrm{a}$ \\
curtume & & & & & & \\
T-6: Terra + adubo + composto & $1.38 \mathrm{a}$ & $4.09 \mathrm{a}$ & $0.58 \mathrm{a}$ & $1.10 \mathrm{a}$ & $5.47 \mathrm{a}$ & $2.02 \mathrm{a}$ \\
urbano & $1.29 \mathrm{a}$ & $2.83 \mathrm{~b}$ & $0.56 \mathrm{a}$ & $1.00 \mathrm{a}$ & $4.12 \mathrm{a}$ & $1.90 \mathrm{a}$ \\
T-7: Terra + adubo + húmus & 1.06 & 3.22 & 0.36 & 0.80 & 4.29 & 1.26 \\
\hline Média & 49.01 & 33.91 & 36.90 & 44.04 & 29.36 & 48.23 \\
\hline CV $(\%)$ & & & & & &
\end{tabular}

Médias seguidas de letras distintas entre si na coluna diferem estatisticamente entre si pelo teste Scott-Knott ao nível de $1 \%$. 
Avaliando a massa fresca total, notou-se que os tratamentos com adição de algum tipo de matéria orgânica no substrato não diferem entre si, onde o T-3 foi superior em $850 \%$ no T-1 e $91 \%$ no T-2. Os tratamentos T-1 e T-2 foram diferentes, para massa fresca total, expressando valores de $0,6 \mathrm{~g}$ e $3,14 \mathrm{~g}$ respectivamente.

Para a variável massa seca total $(\mathrm{g})$ das plantas, não houve diferença significativa entre os T-3, T-4, T-5, T-6 e T-7, no entanto o T-6 apresentou valores consideravelmente mais elevados, sendo superiores $1700 \%$ e $170 \%$ quando comparados aos tratamentos T-1 e T-2 respectivamente. SILVA et al. (2010), avaliando a composição de diferentes substratos e recipientes, notaram que a massa seca total para maracujá amarelo (Passiflora edulis Sims. f. flavicarpa Degener), apresentou peso médio de 0,98 g, utilizando como substrato a terra pura em recipiente de $700 \mathrm{~mL}$, feita com 67 dias após a semeadura e que o solo puro não é recomendado para a produção de mudas de maracujazeiro 'amarelo' favorecendo apenas o comprimento de raiz e massa seca da parte aérea. DANTAS et al. (2015), trabalhando com produção de mudas de Passiflora edulis Sims notaram que ao utilizar doses de esterco bovino na proporção de $49,89 \%$, obtiveram o maior valor de matéria seca total, chegando a 2,04 g e que doses acima desta, proporcionaram decréscimo no teor do mesmo, sendo feitas as análises 42 dias após a semeadura.

\section{CONCLUSÕES}

O desenvolvimento das mudas de maracujazeiro da espécie Passiflora morifolia, foi afetado positivamente pela adição de matéria orgânica no substrato, independente da fonte de matéria orgânica usada, apresentando sempre características de desenvolvimento superiores às mudas desenvolvidas em substratos sem qualquer fonte de matéria orgânica, adubadas ou não.

Dentre as diferentes fontes de matéria orgânica utilizada como componentes de substrato nesse experimento, identificou-se o composto de resíduos orgânicos apresentou médias iguais ou superiores as demais fontes de matéria orgânica.

\section{REFERÊNCIAS}

AGUIAR, A. V. M.; SILVA, R. M.; CARDOSO, E. A.; MARACAJÁ, P. B.; PIRES, H.; Utilização de espécies de passiflora spp. como porta-enxertos no controle de doenças do maracujazeiro. Agropecuária Científica no Semiárido, v. 6, n. 4, 2011. Disponível em: <http://150.165.111.246/ojspatos/index.php/ACSA/article/viewFile/92/pdf>.

ALBUQUERQUE JUNIOR, C. L.; DANNER, M. A.; KANIS, L. A.; DESCHAMPS, C.; ZANETTE, F.; Enraizamento de estacas semilenhosas de maracujazeiro amarelo (Passiflora actinia Hook). Semina: Ciências Agrárias, v. 34, n. 6 Supl 1, p. 36633668, 2013. Disponível em: <http://dx.doi.org/10.5433/16790359.2013v34n6Supl1p3663>. doi: 10.5433/1679-0359.2013v34n6Supl1p3663

ALMEIDA, G. Q.; DE OLIVEIRA SILVA, J.; CABRAL, L. T. S.; MATOS, G. R.; MENEGUCI, J. L. P.; Influência da iluminação artificial no florescimento dos parentais de híbridos de maracujá (Passiflora edulis). Multi-Science Journal, v. 1, n. 2, p. 117-123, 2015. Disponível em: <https://www.ifgoiano.edu.br/periodicos/index.php/multiscience/article/view/87>. 
ARAÚJO, F. F.; TIRITAN, C. S.; PEREIRA, H. M.; JÚNIOR, O. C.; Desenvolvimento do milho e fertilidade do solo após aplicação de lodo de curtume e fosforita. R. Bras. Eng. Agríc. Ambiental, v. 12, n. 5, p. 507-511, 2008. Disponível em: <http://dx.doi.org/10.1590/S1415-43662008000500011>. doi: 10.1590/S141543662008000500011

BERILLI, S. S.; QUIUQUI, J. P. C.; REMBINSKI, J.; SALLA, P. H. H., BERILLI, A. P. C. G.; LOUZADA, J. M.; Utilização de lodo de curtume como substrato alternativo para produção de mudas de café conilon. Coffee Science, v. 9, n. 4, p. 472-479, 2014. Disponível

em: <http://www.coffeescience.ufla.br/index.php/Coffeescience/article/view/728>.

BROETTO, D.; BOTELHO, R. V.; MÜLLER, M. M. L.; KAWAKAMI, J.; TREMEA, A.; Substratos para produção orgânica de mudas de maracujazeiro-azedo. Revista Brasileira de Agroecologia, v. 4, n. 2, 2009. Disponível em: <http://abaagroecologia.org.br/revistas/index.php/rbagroecologia/article/view/8500 >.

CANESIN, R. C. F. S. \& CORRÊA, L. S. Uso de esterco associado à adubação mineral na produção de mudas de mamoeiro (Carica papaya L.). Revista Brasileira de Fruticultura, Jaboticabal, v. 28, n. 3, p. 481-486, 2006. Disponível em: <http://dx.doi.org/10.1590/S0100-29452006000300031 >. doi: 10.1590/S010029452006000300031

DANTAS, A. H.; SILVA, R. M. D.; GARCIA, K. G. V.; AGUIAR, A. V. M. D.; CARDOSO, E. D. A.; Produção de mudas de maracujazeiro amarelo sob adubação orgânica. Agropecuária Científica no Semiárido, v. 11, n. 1, p. 59-64, 2015. Disponível em: <http://150.165.111.246/ojs-patos/index.php/ACSA/article/view/613 >.

FERREIRA, G.; DETONI, M. A.; TESSER, M. S.; MALAVASI, M. M.; Avaliação de métodos de extração do arilo e tratamento com ethephon N.E. brown pelo teste de germinação e de tetrazólio. Revista Brasileira de Sementes, v. 24, n. 1, p. 248-253, 2002. Disponível em: <http://dx.doi.org/10.1590/S0101-31222002000100035 >. doi: $10.1590 /$ S0101-31222002000100035

GONDIN, J. C.; SILVA, J. B.; ALVES, C. Z.; DUTRA, A. S.; JUNIOR, L. E.; Emergência de plântulas de Schizolobium amazonicum Huber ex Ducke (CAESALPINACEAE) em diferentes substratos e sombreamento. Revista Ciência Agronômica, v. 46, n. 2, p. 329-338, 2015. Disponível em: <http://dx.doi.org/10.5935/1806-6690.20150012 >. doi: 10.5935/18066690.20150012

GONÇALVES, E. O.; PETRI, G. M.; CALDEIRA, M. V. W.; DALMASO, T. T.; SILVA, A. G.; Crescimento de mudas de Ateleia glazioviana em substratos contendo diferentes materiais orgânicos. Revista Floresta e Ambiente, v. 21, n. 3, p. 339348, 2014. Disponível em: <http://dx.doi.org/10.1590/2179-8087.029213>. doi: $10.1590 / 2179-8087.029213$ 
MELETTI, L. M. M..; Avanços na cultura do maracujá no Brasil. Revista Brasileira de Fruticultura, v. 33, n. SPE1, p. 83-91, 2011. Disponível em: <http://dx.doi.org/10.1590/S0100-29452011000500012>. doi: 10.1590/S010029452011000500012

NOGUEIRA, A. C.; SOUZA, P. G.; KRATZ, D.; BASSACO, M. V. M.; Adição de maravalha a substratos comerciais na produção de mudas de Eucalyptus grandis Hill ex Maiden. Ambiência - Revista do Setor de Ciências Agrárias e Ambientais. V.10 N.2 2014. Doi: 10.5935/ambiencia.2014.02.07

NOGUEIRA, G. C. F.; RONCATTO, G.; RUGGIERO, C.; DE OLIVEIRA, J. C.; MALHEIROS, E. B.; Produção de mudas de maracujazeiro-amarelo por enxertia hipocotiledonar sobre sete espécies de passifloras. Revista Brasileira de Fruticultura, p. 237-245, 2011. . Disponível em: <http://dx.doi.org/10.1590/S010029452011005000027>. doi: 10.1590/S0100-29452011005000027

SANTOS, F. E. V.; ARAÚJO, J. M.; ANDRADE, W. C.; COSTA, C. C.; SILVA, A. G.; Formação de mudas de Eucalyptus urophylla ST Blake com utilização de resíduo sólido orgânico urbano. Enciclopédia Biosfera, v. 9, p. 1203-1214, 2013. . Disponível em: $<$ http://www.conhecer.org.br/enciclop/2013a/agrarias/FORMACAO\%20DE\%20MUD AS.pdf>.

SANTOS, J. L.; MATSUMOTO, S. N.; D'ARÊDE, L. O.; LUZ, I. D.; VIANA, A. E. S.; Propagação vegetativa de estacas de Passiflora cincinnata Mast. em diferentes recipientes e substratos comerciais. Revista Brasileira de Fruticultura, v. 34, p. 581-588, 2012. . Disponível em: <http://dx.doi.org/10.1590/S010029452012000200033>. doi: 10.1590/S0100-29452012000200033

SANTOS, P.C.; LOPES, L. C.; FREITAS, S. J.; SOUSA, L. B.; CARVALHO, A. J.; Crescimento inicial e teor nutricional do maracujazeiro amarelo submetido à adubação com diferentes fontes nitrogenadas. Revista Brasileira de Fruticultura, Jaboticabal, v. Especial, p. 722-728, 2011. Disponível em: <http://dx.doi.org/10.1590/S0100-29452011000500101>. doi:10.1590/S010029452011000500101

SILVA, E. A. D.; MARUYAMA, W. I.; MENDONÇA, V.; BARDIVIESSO, D. M.; TOSTA, M. D. S.; Composição de substratos e tamanho de recipientes na produção e qualidade das mudas de maracujazeiro 'amarelo'. Ciênc. agrotec.,(Impr.), v. 34, n. 3, p. 588-595, 2010. Disponível em: <http://dx.doi.org/10.1590/S141370542010000300009 > doi: 10.1590/S1413-70542010000300009

WENDLING, I. \& GATTO A.; Substratos, adubação e irrigação na produção de mudas. Aprenda fácil, 2002. 